\title{
URGENSI TATA KELOLA INOVASI PEREKAMAN DATA DAN DOKUMEN KEPENDUDUKAN
}

\section{URGENCY OF INNOVATION GOVERNANCE OF CIVIL DATA AND DOCUMENT REGISTRATION RECORDS}

\author{
M. Husein Maruapey ${ }^{1 *}$ \\ ${ }^{1}$ Program Studi Administrasi Publik, Fakultas Ilmu Sosial dan Ilmu Politik, Universitas \\ Djuanda, Jl. Tol Ciawi No. 1, Kotak Pos 35 Bogor 16720 \\ *Korespondensi: M. Husein Maruapey. Email: maruapey.husein@gmail.com
}

(Diterima: 4 Maret 2019; Ditelaah: 19 Maret 2019; Disetujui: 29 Maret 2019)

\begin{abstract}
Managing innovation involves many complex activities from organizations, stakeholders, and knowledge. Innovation is essential in improving the efficiency of the public sector. So the importance of governance innovation will provide the consequences of any failure or success of the innovation itself. Governance innovation also reflects the managing innovation in a way that is innovative as one strategy innovation process, so that innovation can show results and benefits. The focus of this research is the investigation phenomenon of governance innovations data and documents civil registration record with innovative ways in Southeast Aceh Regency. Also comparative with some other local government do it. Methods of qualitative analysis with phenomenology are used to be able to explain and illustrate and identify how the phenomenon occurs. Data collection is done inductively, interview, discussion, observation, and participation. Data reduction do with descriptive between empirical and secondary data. Images, tables, symbols, and lines used to realities revealed. Triangulation is used to conclude carefully from empirical and secondary data. The results of this research finding, governance innovation are innovative should be supported by policies, aside from the leadership capability as the executor. Citizen participation, cooperation various sector also contributes to a positive endorsement. Innovation is also an immediate need at this time for delivering excellent public services and competitive by the government.
\end{abstract}

Keywords: Innovation Governance, Innovative, Public Service, Government.

\begin{abstract}
ABSTRAK
Mengelola inovasi melibatkan banyak aktivitas kompleks dari berbagai jenis organisasi, stakeholder, dan pengetahuan. Inovasi sangat penting dalam meningkatkan efisiensi sektor publik. Begitu pentingnya tata kelola inovasi akan memberikan konsekuensi timbulnya kegagalan atau kesuksesan inovasi itu sendiri. Tata kelola inovasi juga mencerminkan mengelolaan inovasi dengan cara yang inovatif sebagai salah satu strategi proses inovasi, agar inovasi bisa menunjukkan hasil dan manfaatnya. Fokus penelitian ini adalah penyelidikan fenomena pengelolaan inovasi secara inovatif pada sektor pengelolaan data dan dokumen kependudukan di Kabupaten Aceh Tenggara. Selanjutnya akan dikomparasikan dengan beberapa daerah yang juga melakukan pengelolaan data dan dokumen kependudukan secara inovatif. Metode kualitatif dengan analisis fenomenologi digunakan untuk dapat menjelaskan dan menggambarkan serta mengidentifikasi bagaimana fenomena itu terjadi. Pengumpulan data dilakukan secara induktif, wawancara, diskusi, dan observasi partisipasi. Reduksi data dilakukan dengan deskriptif antara data penyelidikan empiris, dan data sekunder. Gambar, tabel, simbol, dan garis digunakan untuk menggungkapkan realitas yang ada. Triangulasi digunakan untuk menarik kesimpulan secara hati-hati dari data empiris dan data sekunder. Hasil penelitian ini menemukan, pengelolaan inovasi secara inovatif harus didukung oleh berbagai kebijakan pendukung, selain dari kapasitas pimpinan sebagai eksekutor. Partisipasi masyarakat, kerjasama lintas batas juga memberikan kontribusi dukungan yang positif. Inovasi juga merupakan kebutuhan yang mendesak saat ini untuk menghantarkan pelayanan publik yang baik dan kompetitif oleh pemerintah.
\end{abstract}

Kata Kunci: Tata Kelola Inovasi, Inovatif, Pelayanan Publik, Pemerintah.

M. Husein Maruapey. 2019. Urgensi Tata Kelola Inovasi Perekaman Data dan Dokumen Kependudukan. 


\section{PENDAHULUAN}

Tahun 2017, Population Reference Bureau mengeluarkan world population data dan Indonesia menjadi negara ke 4 terbesar di dunia dalam jumlah penduduk dengan angka 264 juta jiwa di bawah China, India, dan Amerika Serikat. Jumlah penduduk yang besar tersebut menjadikan pemerintah berkepentingan dan berkewajiban memiliki data yang akurat. Data tersebut sangat penting digunakan untuk memetakan jumlah penduduk miskin, pelayanan publik, perencanaan pembangunan, alokasi anggaran, pembangunan demokrasi, dan penegakan hukum. Bertujuan untuk identifikasi diri dan sebagai bahan merumuskan setiap kebijakan strategis yang bersentuhan langsung dengan masyarakat.

Pengelolaan data dan dokumen kependudukan diperlukan perubahan untuk menata dan mengelola data secara modern. Undang-Undang Nomor 24 Tahun 2013 tentang Administrasi Kependudukan mensyaratkan untuk penataan, penerbitan dokumen dan data kependudukan secara akurat. Pelayanan administrasi kependudukan yang profesional, memenuhi standar teknologi informasi, dinamis, tertib, dan tidak diskriminatif dalam pencapaian standar pelayanan minimal menuju pelayanan prima yang menyeluruh untuk mengatasi permasalahan kependudukan. Seharusnya fenomena pertumbuhan jumlah penduduk dapat dikelola dengan baik oleh negara melalui Dinas Kependudukan dan Pencatatan Sipil sebagai institusi pelaksana urusan administrasi kependudukan. Penggunaan teknologi dalam perekaman data dan dokumen kependudukan akan menimbulkan efisiensi dan kepastian waktu produksi dokumen kependudukan. Pembuatan dokumen kependudukan adalah gratis dan diatur dalam kebijakan pemerintah. Fakta nya, per januari 2017 masih terdapat 21.058 jiwa penduduk Kabupaten Aceh Tenggara yang belum terdaftar (Disdukcapil Kabupaten Aceh Tenggara, 2017). Secara nasional masih ada sekitar 9,3 juta penduduk yang belum melakukan perekaman data dan dokumen kependudukan atau setara dengan 5 persen dari jumlah penduduk nasional (Andayani, 2017).

Salah satu cara penataan, penerbitan dokumen dan data kependudukan itu melalui inovasi. Inovasi menjadi suatu kebutuhan obyektif untuk meningkatkan kinerja birokrasi menjadi lebih efektif (McHugh, O'Brien, \& Ramondt, 2010; Dwiyanto, 2015). Inovasi juga bukan sesuatu yang sederhana yang datang dengan sebuah gagasan tapi termasuk dengan penerapannya, proses integrasinya ke sistem dan pemantauan hasilnya dalam jangka panjang (Klimentova, 2014). Tapi probabilitas alternatif cara baru itu lebih unggul dari pada cara sebelumnya (Rogers, 1995). Beberapa contoh model inovasi yang berkaitan dengan data dan dokumen kependudukan juga pernah dilakukan dan telah termanifestasi secara global. Misalnya, Korea Selatan melakukan inovasi e-people, bertujuan memperbaiki efisiensi administratif data kependudukan untuk memberikan transparansi dan berkontribusi lebih terhadap prinsipprinsip good governance (OECD, 2016).

Indonesia melalui Kabupaten Gunung Kidul dengan layanan sentuh (touchscreen) yang memuat informasi tentang berbagai layanan administrasi kependudukan. Pemakaian banyak media informasi melalui tatap muka, radio lokal, buku saku, leaflet, pamplet, spanduk, pameran kependudukan. Program jemput bola dengan mobil keliling, perbaikan pendaftaran dengan sistem elektronik untuk memberikan kepastian tertib administrasi. Pengarsipan dengan manual dan elektronik (Disdukcapil Kabupaten Gunung Kidul, 2016). Kabupaten Gresik dengan inovasi Kartu Keluarga Kudata Ulang (Kakekku Datang). Ide ini dimulai dari banyaknya Kartu Keluarga yang tidak pernah diperbaharui, masih terdapat banyaknya data ganda, dan data anomali. Tujuannya, untuk memerbaharui data kependudukan dan hampir 70 persen data tersebut tidak diperbaharui sejak 2008. Pola pelaksanaan melalui kegiatan 
pro aktif (jemput bola) dengan mendatangi desa/kelurahan (Kemanpan RB, 2017).

Bentuk-bentuk inovasi itu membutuhkan pengelolaan agar dapat menunjukkan hasil dan manfaatnya. Mengelola inovasi akan melibatkan banyak aktivitas kompleks dari berbagai jenis kegiatan birokrasi dan inovasi itu sendiri untuk mencapai tujuan secara efektif dan efisien. Kegiatan itu setidaknya mencakup unsur perencanaan dan pengambilan keputusan, penetapan tujuan, koordinasi, kepemimpinan, dan pengembangan. Oleh sebab itu birokrasi akan lebih mudah untuk menanggapi kemungkinan tekanan dari internal dan eksternal, memperkenalkan kreativitas untuk menumbuhkan berbagai cara/ide, produk, layanan dan proses yang dianggap baru. Lebih lanjut pengelolaan inovasi dapat didorong oleh kemampuan birokrasi untuk mengadopsi berbagai bentuk inovasi pengelolaan berdasarkan tingkat kebutuhan yang mendesak. Beberapa ahli juga mengklaim bahwa kesulitan birokrasi berinovasi menjadi salah satu sebab birokrasi itu seperti tidak berfungsi dengan baik (Goodsell, 2015; Hummel, 2015). Ideal nya dari sisi tujuan dalam lingkup birokrasi pemerintah, inovasi dapat menekan masalah korupsi, kolusi dan nepotisme (Klareskov \& Nikolov, 2007), berkontribusi terhadap kinerja dan efektivitas organisasi (Damanpour \& Aravind, 2011). Dalam lingkup pelayanan, inovasi dipercaya akan meningkatkan kualitas pelayanan lebih efektif dan efisien (Vries, Bekkers, \& Tummers, 2015). Memaksimalkan sumber daya manusia dan mengembalikan kepercayaan publik terhadap pemerintah (Alberti \& Bertucci, 2007). Gagasan inovasi bagi institusi pemerintah juga diatur dalam UndangUndang Republik Indonesia Nomor 23 Tahun 2014 tentang Pemerintah Daerah pada BAB XXI pasal 386 ayat 1 .

Pengelolaan inovasi dapat ditemukan diberbagai sektor, beberapa studi yang pernah dilakukan dapat menjadi informasi yang penting bahwa inovasi perlu dikelola dengan cara-cara yang inovatif. Chung (2011) dalam penyelidikannya tentang bioteknologi di Taiwan dengan mengkonfigurasi tiga sektor, yaitu obatobatan, pertanian, dan perangkat medis. Untuk mengelola berbagai bentuk inovasi dalam sektor itu pemerintah Taiwan dalam kurun waktu 2000-2008 secara intensif memromosikan banyak kebijakan untuk mendukung pengembangan bioteknologi dan sektor terkait. Selain itu, proses pembuatan kebijakan akan membentuk isi dari kesesuaian kebijakan (research, technology, development, innovation) berkaitan tentang konfigurasi sistem inovasi nasional, sektoral, dan teknologi.

Konsep tata kelola inovasi (governance innovation) menunjukkan gagasan, eksperimen dan praktik baru yang dapat membantu mencapai koordinasi yang lebih baik dan hasil yang lebih umum (Moore \& Hartley, 2008; Anttiroiko, Bailey, \& Valkama, 2011; Scupola \& Zanfei, 2016). Tata kelola inovasi dapat memromosikan kapasitas inovasi sektor publik, dengan alasan bahwa sering dipandang sebagai alternatif seharusnya lebih dipandang sebagai pelengkap. Beberapa teori administrasi publik seperti new public service theory, administrative reform, contingency theory, innovation theory, institutional theory, governance theory (Damanpour, 1996; Caiden, 2009; Bovaird \& Löffler, 2009; Anttiroiko, Bailey, \& Valkama, 2011; Torfing \& Triantafillou, 2016), berkontribusi menghasilkan korelasi positif antara bentuk interaktif tata kelola dan inovasi sektor publik. Anttiroiko, Bailey dan Valkama (2011:13) menyebut, there are also concepts that refer to application areas of governance innovation, such as democratic, managerial, development and service functions of government. Penelitian ini lebih berfokus kepada penyelidikan fenomena penggelolaan inovasi secara inovatif pada sektor pengelolaan data dan dokumen kependudukan di Kabupaten Aceh Tenggara. Selanjutnya akan dikomparasikan dengan beberapa daerah yang juga melakukan penggelolaan data dan 
dokumen kependudukan secara inovatif. Pendekatan konseptual teoritik Anttiroiko, Bailey dan Valkama (2011) digunakan untuk dapat mengeksplorasi lebih jauh mekanisme pengelolaan yang inovatif tersebut. Oleh sebab itu pertanyaan yang paling relavan adalah bagaimana fenomena penggelolaan inovasi secara inovatif dilakukan melalui faktor democratic, managerial, development and service functions of government?

\section{MATERI DAN METODE}

Artikel penelitian ini sebagai penelitian kualitatif, analisis fenomenologi digunakan untuk dapat menjelaskan dan menggambarkan serta mengidentifikasi bagaimana fenomena itu terjadi. Penggumpulan data dilakukan secara induktif, wawancara, diskusi, dan observasi partisipasi. Wawancara mendalam dilakukan kepada 37 informan yang terdiri dari 23 aktor kebijakan, 10 orang dengan masyarakat, dan 4 orang kelompok civil society. Epistimologis analisis fenomenologi berbasis pengetahuan pribadi dan subjektivitas dan menekankan pentingnya perspektif pribadi dan interpretasi (Moustakas, 1994; Groenewald, 2004). Fenomena adalah hal-hal yang dapat diamati oleh panca indra manusia dan dapat diterangkan dan dinilai secara ilmiah. Oleh sebab itu analisis fenomenologi sangat efektif untuk membawa pengalaman dan persepsi orang untuk dapat menggambarkan atau menentang asumsi struktural dan normatif. Analisis ini dapat ditambahkan dimensi interpretatif, dan memungkinkan digunakan untuk membangun dasar teori praktis, memungkinkan untuk menginformasikan dukungan atau tantangan kebijakan dan tindakan.

Pemilihan informan dilakukan secara criterion-based selection yaitu agar manusia, latar belakang, kejadian tertentu (unik, khusus, tersendiri, aneh) betul-betul diupayakan terpilih atau disertakan untuk memberikan informasi penting yang berkaitan dengan tema penelitian. Aktor kebijakan terdiri dari eksekutif dan legislatif, masyarakat terdiri dari pemuka masyarakat yang mewakili sebahagian masyarakat di 8 kecamatan (Babussalam, Lawe Bulan, Deleng Pokhisen, Bambel, Semadam, Lawe Sigala-gala, Badar, Lawe Alas) yang ada di Kabupaten Aceh Tenggara dengan kriteria 4 Kecamatan berada dengan jarak terdekat dengan ibukota Kabupaten, 4 Kecamatan yang berada dengan jarak tempuh melebihi $20 \mathrm{Km}$ diluar ibukota Kabupaten yang memengaruhi aksesbilitas masyarakat untuk pengurusan administrasi dokumen kependudukan. Kelompok civil society terdiri dari 3 pimpinan kelompok kepentingan (LSM) dan 1 orang akademisi. Kelompok masyarakat dan civil society dipilih dengan syarat knowledgeable on the subject.

Selanjutnya hasil penyelidikan akan direduksi dengan model deskriptif antara data penyelidikan empiris, dan data sekunder di bagian hasil dan pembahasan. Gambar, tabel, simbol, dan garis digunakan untuk menggungkapkan realitas yang ada. Pada akhirnya digunakan triangulasi untuk menarik kesimpulan secara hati-hati dari data empiris dan data sekunder baik yang tersedia secara nasional dan internasional. Giorgi (1997) memberikan panduan langkah untuk melakukan analisis fenomenologi yaitu: (1) the phenomenological reduction, (2) description, and (3) search for essences.

\section{HASIL DAN PEMBAHASAN}

\section{Sejarah Singkat Dokumen Kependuduk- an di Indonesia}

Indonesia mengalami beberapa transformasi bentuk dokumen kependudukan sebagai upaya pencatatan yang terus berkembang dari waktu ke waktu. Transformasi itu dimulai dari jaman penjajahan Belanda, Jepang, awal kemerdekaan (1945), Periode 1967-1970, Periode 1970-1977, Periode 1977-2002, Periode 2002-2004, Periode 2003 (khusus 
untuk masyarakat provinsi Aceh terjadi konflik bersenjata yang disebut KTP merah putih), Periode 2004-2011 disebut KTP Nasional. Dari periode penjajahan Belanda sampai periode Januari tahun 2011 masih menggunakan pengelolaan data dan dokumen kependudukan secara manual. Kertas, warna, ukuran yang berbeda digunakan sebagai upaya transformasi, namun data yang dicatat sering menimbulkan data yang tidak akurat, karena sistem pencatatan masih berkonsentrasi di tingkat lokal, belum terintegrasi secara nasional.

Pada Februari tahun 2011 diupayakan untuk membuat keseragaman secara nasional dengan memanfaatkan elektronik (KTP-el) yang diyakini menghemat anggaran negara, dan anti manifulasi data. KTP-el yang diterapkan oleh Indonesia memiliki keunggulan dibandingkan dengan negara seperti Cina dan India. Cina hanya menggunakan chip data perorangan terbatas pada kartunya tanpa adanya data biometrik, India menggunakan sistem UID (Unique Identification Data) untuk pengelolaan data dilakukan melalui hotspot pelayanan yang terbatas. Namun KTP-el Indonesia mengkombinasikan keunggulan yang lain yaitu chip sebagai data perorangan, biometrik (sidik jari dan iris mata) dan UID (UID, Nomor Induk Kependudukan) dan sampai saat ini proses perekaman dilaksanakan lebih dari 6.214 kecamatan yang ada di Indonesia (Dirjen Dukcapil, 2014).

\section{Konsep Tata Kelola Inovasi (Governance Innovation)}

Inovasi tidak hanya berfokus pada perubahan kongkret dalam hal tertentu yang dihasilkan melalui proses inovasi, tetapi juga pada cara mengelola aktivitas inovasi yang digunakan sebagai standar normatif. Dalam mempertimbangkan masa depan inovasi di sektor publik, governansi inovasi merupakan bagian yang signifikan. Ada kemungkinan bahwa inovasi akan terus berkembang dengan cara baru yang mengarah kepada inovasi yang lebih sederhana, mudah dipahami, dan murah biaya (Moore \& Hartley, 2008; Vries, Bekkers, \& Tummers, 2015).

Argumentasi lain juga menyebut bahwa inovasi perlu dikelola dengan baik agar menunjukkan hasilnya (Hartley, 2005; Alberti \& Bertucci, 2007; Moore \& Hartley, 2008; Anttiroiko, Bailey, \& Valkama, 2011; Torfing \& Triantafillou, 2016). Maka, tata kelola inovasi tampak sangat berbeda dari inovasi dalam bentuk produk, layanan, dan proses (Scupola \& Zanfei, 2016). Konsep ini dibangun dengan menggabungkan dua konsep yang berbeda yaitu konsep inovasi dan tata kelola (governance). Untuk mereduksi beberapa konseptual teoritis tentang tata kelola inovasi dari berbagai praktisi dan akademisi dapat dilihat pada Tabel 1:

Tabel 1. Konseptual Teoritis Tata Kelola Inovasi

\begin{tabular}{ll}
\hline \multicolumn{1}{c}{ Nama } & \multicolumn{1}{c}{ Teori Tata Kelola Inovasi } \\
\hline Hartley (2005) & $\begin{array}{l}\text { Innovation, Improvement, } \\
\text { Role of Policy-Makers, Role of } \\
\text { Public Managers, and Role of } \\
\text { Population }\end{array}$ \\
\hline Alberti dan & $\begin{array}{l}\text { Integrating services; } \\
\text { Decentralizing service delivery } \\
\text { and monitoring; Utilizing }\end{array}$ \\
& $\begin{array}{l}\text { partnerships; } \text { Engaging } \\
\text { citizens; and Taking } \\
\text { advantage of information and }\end{array}$ \\
& Communication technologies. \\
\hline Anttiroiko, & $\begin{array}{l}\text { Democratic, Managerial, } \\
\text { Development and Service }\end{array}$ \\
Valley, dan & Functions of Government.
\end{tabular}

Sumber: Hartley (2005); Alberti dan Bertucci (2007); Anttiroiko, Bailey, dan Valkama (2011).

Pengelolaan inovasi terkait dengan bagaimana inovasi dikelola, dan bagaimana sebuah organisasi bergerak dari sebuah gagasan ke produk jadi atau layanan. Memahami dan mengelola inovasi tersebut adalah salah satu isu yang paling banyak dalam administrasi publik di dunia 
kontemporer (Osborne \& Brown, 2011; Torfing \& Triantafillou, 2016). Salah satu yang menarik dari berbagai konseptual teoritis di atas, mereka paling sering membahas bagaimana partisipasi masyarakat. Masyarakat adalah objek pelayanan dan bagaimana mereka memberikan tanggapan berupa kritik dan saran untuk bahan pertimbangan pengembangan inovasi. Hartley (2005) memberikan pemahaman bahwa tata kelola inovasi (governance innovation) adalah new forms of citizen engagement, and democratic institutions (for example area forums; devolved government). Lebih lanjut, Anttiroiko, Bailey, dan Valkama (2011:13) menyebut innovation in public governance focuses on the 'public domain' to solve problems. Permasalahan yang sering terjadi dalam pemerintah adalah pelayanan publik. Pelayanan publik sering dianggap sebagai hal penting dari berbagai konsep pelayanan publik. Bagaimana pemerintah berusaha untuk selalu menghadirkan pelayanan publik yang baik. Berbagai gerakan reformasi pemerintah dilakukan untuk memperbaiki pelayanan publik yang telah termanifestasi secara global.

\section{Inovasi Sektor Publik}

Berbagai bentuk inovasi dilakukan dengan pemanfaatan teknologi yang paling sering digunakan. Saat ini tekanan pada sektor publik untuk menjadi inovatif adalah sebesar yang pernah ada. Banyak argumentasi yang merangkul gagasan bahwa inovasi berkontribusi untuk meningkatkan pemecahan masalah organisasi pemerintah untuk menghadapi berbagai tuntutan masyarakat yang semakin kompleks, dan juga meningkatkan kualitas pelayanan publik (Sorensen \& Torfing, 2011; Vries, Bekkers, \& Tummers, 2015). Selain para praktisi dan akademisi memberikan berbagai argumentasi tujuan inovasi sektor publik, organisasi seperti OECD, UNDP, Ernst \& Young Global memberikan beberapa tujuan mengapa pemerintah melakukan inovasi sektor publik. Misalnya Ernst \& Young Global memberikan pandangan tujuan pemerintah melakukan inovasi sektor publik untuk optimal resource allocation, competitive advantage, credibility, talent retention and attraction, enabling the private sector (Ernst \& Young, 2017). Oleh sebab itu inovasi sektor publik akan memaksimalkan sumber daya yang dikeluarkan oleh pemerintah. Selama ini cara-cara tradisional diyakini menyerap anggaran pemerintah yang besar. Adopsi cara baru melalui inovasi akan memberikan setidaknya kepastian waktu, kualitas pelayanan publik, efisiensi anggaran, dan meningkatkan kepercayaan publik terhadap pemerintah. Partisipasi masyarakat dan pihak ketiga akan memungkinkan inovasi sektor publik akan berkembang dari waktu ke waktu. Inovasi terbaik dicapai melalui pelembagaan kolaborasi diantara pemangku kepentingan interdependen dengan cara memperkuat kapasitas inovasi sektor publik, dan dapat dicapai dengan mengenali pengerak dan hambatan inovatif untuk berkompetisi serta kolaborasi (Sorensen \& Torfing, 2011; Agger \& Sorensen, 2016).

\section{Tata Kelola Inovatif Data dan Dokumen Kependudukan}

Tata kelola inovatif dalam penelitian ini akan mengeksplorasi lebih jauh penggelolaan inovasi data dan dokumen kependudukan di Kabupaten Aceh Tenggara. Selanjutnya akan dikomparasikan dengan pengelolaan inovasi secara inovatif data dan dokumen kependudukan pada daerah lain untuk mendapatkan realitas yang ada. Di saat yang sama akan diberikan argumentasi dari beberapa praktisi dan akademisi melalui literatur ilmiah yang tersedia. Diharapkan pembahasan dalam artikel penelitian ini memberikan sumbangan wawasan pengetahuan mengenai cara mengelola inovasi dengan cara yang inovatif. Tentunya pembahasan ini akan diarahkan oleh konseptual teoritis yang menjadi landasan yaitu melalui faktor democratic, managerial, development and service functions of government seperti terlihat pada Gambar 1: 


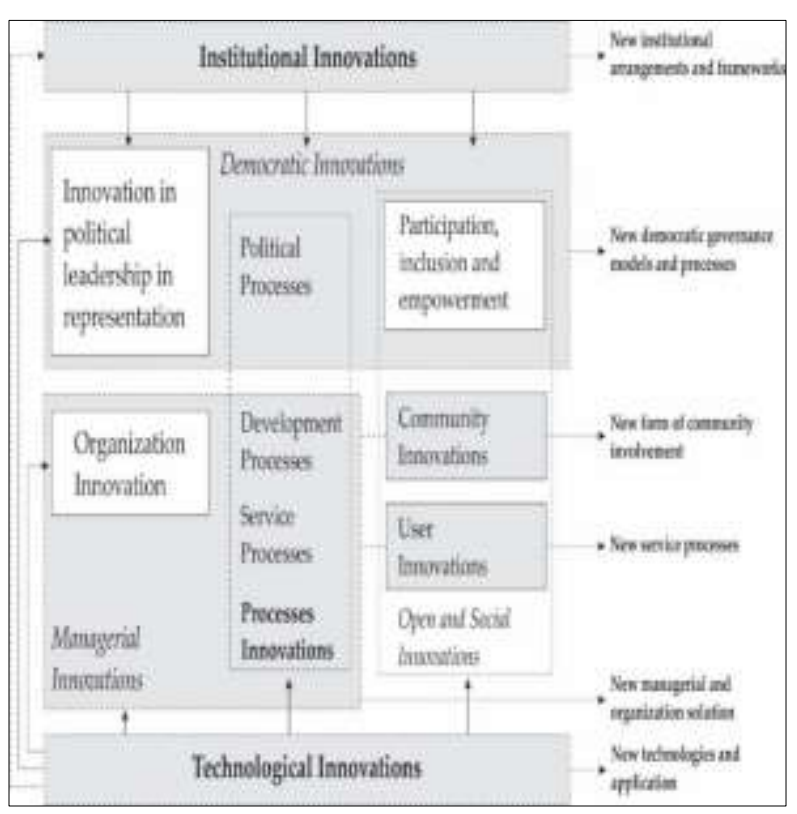

Sumber: Anttiroiko, Bailey, \& Valkama (2011: 14)

Gambar 1. Innovation Concepts in the Field of Public Governance

\section{Democratic}

Democratic dalam pandangan Anttiroiko, Bailey dan Valkama (2011) merujuk kepada mekanisme proses politik yang dilakukan antara eksekutif dan legislatif untuk menghasilkan berbagai macam produk kebijakan. Contoh, anggaran adalah salah satu menu utama bagi birokrasi untuk dapat menjalankan berbagai program (Willoughby, 2014). Namun tidak selalu anggaran yang diusulkan oleh pemerintah dapat dengan mudah disetujui oleh legislatif. Ada mekanisme yang harus dilalui dan kenyataannya usulan anggaran biasanya bermula dari identifikasi urgensi usulan dari eksekutif. Perlu kondisi politik yang kondusif dibangun oleh pimpinan daerah untuk menghasilkan berbagai kesepakatan penggunaan anggaran. Disisi yang lain eksekutor adalah tetap wewenang pimpinan daerah sebagai pengguna anggaran.

Menghasilkan berbagai kebijakan tingkat lokal harus didukung oleh situasi politik yang kondusif sehingga dapat menghasilkan kebijakan dan kesepakatan sumber daya untuk mengelola inovasi.
Beberapa kondisi seperti pergantian kepemimpinan daerah dan relasi politik juga turut memberi pengaruh untuk menghasilkan kebijakan tingkat lokal (Morrell \& Hartley, 2006; Cerne, Jaklic, \& Skerlavaj, 2013; Lewis, Ricard, \& Klijn, 2017). Partisipasi pimpinan daerah untuk mendorong dan mendukung inovasi juga diperlukan. Kesuksesan inovasi tidak hanya didukung kebijakan namun harus juga didukung oleh berbagai pihak lintas batas seperti sumber daya manusia berbagai pihak, kolaborasi, partisipasi masyarakat, civil society yang dapat mendorong dinamisme proses politik lebih kondusif.

Faktanya di Kabupaten Aceh Tenggara, walaupun telah ada Qanun Kabupaten Aceh Tenggara Nomor 80 Tahun 2013 sebagai derivate UU 24/2013 untuk menyelenggarakan administrasi kependudukan, sepertinya perhatian khusus pimpinan daerah terhadap masalah administrasi kependudukan belum menunjukkan perbaikan. Dalam kurun waktu tahun 2011-2018 anggaran daerah lebih banyak diarahkan dalam bentuk proyek pembangunan infrastruktur jalan dan sektor lainnnya. Diakui masalah administrasi kependudukan dari tahun ke tahun menimbulkan masalah yang sama, artinya masalah yang telah terdeteksi tidak pernah diupayakan untuk dilakukan perbaikan. Seperti gedung kantor yang tidak layak, masih banyaknya data ganda, pungutan liar, serta alur pelayanan yang berbelit dan panjang. Sebab administrasi kependudukan merupakan salah satu pelayanan publik yang paling dasar selain kesehatan dan pendidikan.

Ada pola klientelisme dan patronase dalam pemilihan langsung pimpinan daerah yang memberikan kontribusi keuntungan kepada kelompok tertentu melalui kegiatan pemerintah (Aspinall \& Sukmajati, 2015). Pola ini menjadi awal menuju kepada praktik-praktik balas jasa, bukan hanya sekedar wewenang dan tanggung jawab dalam esensi kekuasaan setelah terpilih. Namun tuntutan dan janji-janji secara 
ekplisit maupun implisit berlahan akan direalisasikan. Terkadang tuntutan, janjijanji itu akan menjelma sebagai prioritas utama. Pada praktiknya saling memberi dan menerima menjadi cerminan kualitas seorang pimpinan. Tidak bisa hanya mengukur visi dan misi yang telah terkonseptualisasi, namun aksi nyata, tanggung jawab pimpinan daerah kepada rakyatnya harus menjadi prioritas utama melalui saluran birokrasi pemerintah yang dipimpin. Ketika pola-pola kolusi, nepotisme, klientelisme, dan patronase menjadi dominan dalam aktivitas birokrasi, maka birokrasi sepertinya akan menjadi eksploitasi politik.

Kejadian seperti ini bukanlah sesuatu yang normal untuk meningkatkan kinerja pemerintah. Bahkan Sjahrir, Kis-Katos, dan Schulze (2013) dalam penyelidikannya menemukan, proses politik anggaran pemerintah daerah di Indonesia lebih cenderung karena kausalitas pemilukada. Perilaku pimpinan akan turut menyesuaikan terhadap berbagai macam tekanan dan permintaan dari internal dan eksternal. Misalnya studi yang dilakukan oleh Morrell dan Hartley (2006) mengidentifikasi pemimpin politik pemerintah daerah di Inggris dan Wales menemukan bahwa perilaku kepemimpinan politik selalu didominasi atas panutan seorang sosok, latar belakang, dan lebih kecil porsinya melihat keunggulan sumber daya manusia yang dimiliki. Oleh sebab itu diperlukan pimpinan yang melayani masyarakat secara baik dan bijak.

Kejadian ini sangat berbeda dengan Kabupaten Padang Pariaman misalnya, menganggap persoalan administrasi kependudukan merupakan salah satu prioritas utama. Legislatif, eksekutif bersinergi untuk melakukan langkahlangkah perubahan, mendukung inovasi, dan program dibidang administrasi kependudukan (Disdukcapil Kabupaten Padang Pariaman, 2017). Peran pimpinan daerah menjadi dominan untuk terus melakukan perubahan dengan serangkaian program melalui SKPK (Satuan Kerja
Perangkat Kabupaten). Langkah-langkah kebijakan berkenaan dengan keputusan tentang apa yang harus dikerjakan, dimensi kebijakan ini dianalogikan dengan pekerjaan otak yang selalu memutuskan apa yang hendak dikerjakan oleh sistem tubuh.

\section{Managerial}

Saat ini kemampuan mengelola inovasi menjadi sukses menjadi dilemma, bila pimpinan minim pengetahuan, tidak berkompetensi sehingga akan sulit menerima inovasi (Borins, 2002; Francisco, 2012). Keadaan ini muncul akibat penempatan seorang pimpinan lebih banyak didasari pada kolusi dan nepotisme. Kegiatan manajerial melibatkan kemampuan mengelola dan pengetahuan pimpinan. Fungsi manajerial merencanakan dan melibatkan penetapan tujuan dan mencari cara untuk mencapainya. Lebih lanjut perencanaan dianggap sebagai fungsi utama manajemen, mencakup semua hal yang dilakukan berkontribusi untuk fungsi manajemen lainnya. Memastikan sumber daya yang tersedia, koordinasi, kerjasama tim, desentralisasi kewenangan dan kepercayaan untuk melaksanakan rencana yang menjadi tujuan (DuBrin, 2006). DuBrin (2006) membagi kriteria kemampuan manajerial seorang pimpinan menjadi technical skill, interpersonal skill, conceptual skill, diagnostic skill, and political skill.

Technical skill, keterampilan melibatkan pemahaman dan kemampuan secara spesifik. Keterampilan meliputi kemampuan menyiapkan anggaran, metode, proses, prosedur, atau teknik (hard skill). Keterampilan dalam bentuk hubungan manusia (interpersonal skill) adalah kemampuan pimpinan untuk bekerja secara kolektif sebagai anggota tim dan membangun usaha yang kooperatif (soft skill). Conceptual skill, kemampuan untuk melihat organisasi sebagai entitas total. Ini termasuk mengenali berbagai unit organisasi saling bergantung satu sama lain. Diagnostic skill, keterampilan yang sering membutuhkan keterampilan lain, karena 
pimpinan harus menggunakan keterampilan teknis, manusia, konseptual, atau politis untuk memecahkan masalah yang didiagnosa. Political skill, pada umumnya pimpinan akan menggunakan keterampilan politik untuk memeroleh kekuatan yang diperlukan untuk mencapai tujuan. Faktor pimpinan akan memberikan pengaruh yang signifikan dalam memotivasi bawahannya untuk terus menghasilkan ide/cara kreatif. Ketika pimpinan menjadi role model inovasi maka kebiasaan pimpinan dalam birokrasi akan dicontoh oleh bawahannya (Borins, 2002; Cerne, Jaklic, \& Skerlavaj, 2013; Banerjee \& Ceri, 2016; Su \& Baird, 2017).

Sebagai contoh, salah satu fungsi manajerial adalah memastikan fungsi analisis, perencanaan, pengambil keputusan, dan pengembangan berjalan dengan efektif. Namun pimpinan yang tidak sesuai dengan kompetensi akan sulit untuk mengembangkan inovasi. Dibutuhkan kemampuan analisis dan konseptualisasi yang dapat melahirkan berbagai keputusan pengembangan inovasi untuk menjamin siklus hidup inovasi dengan tujuan menjamin keberlangsungan inovasi, menilai dan mengembangkan inovasi tanpa tergantung pada model yang telah ada. Selain itu, manajer berkewajiban untuk memastikan proses pelayanan berjalan dengan baik.

Penggunaan mobil keliling, dan call center adalah beberapa inovasi yang dilakukan oleh Pemerintah Kabupaten Aceh Tenggara melalui Dinas Kependudukan dan Pencatatan Sipil. Proses pelayanan yang diberikan mobil keliling cukup memberikan kontribusi pelayanan administrasi kependudukan yang baik kepada masyarakat dengan turun langsung ditengah-tengah masyarakat. Namun keberadaan mobil keliling ini kurang mendapat respon yang baik dari masyarakat, disebabkan oleh koordinasi yang buruk dengan kecamatan. Sering kecamatan tidak mengetahui mobil keliling akan berkunjung. Akibatnya pihak kecamatan tidak bisa memberikan informasi kepada masyarakat melalui kepala desa, agar ditindaklanjuti kepada masyarakat.

\section{Development}

Pengembangan inovasi memerlukan kerjasama antara berbagai sektor. Contoh, ketika inovasi telah diimplementasikan, tidak semua masyarakat akan merespon inovasi tersebut. Penyebabnya adalah tingkat pengetahuan yang minim akan memaksa birokrasi melakukan berbagai usaha promosi, kurangnya sosialisasi menyampaikan informasi tentang inovasi yang dilaksanakan, sehingga menyebabkan rendahnya tingkat partisipasi masyarakat. Secara teori partisipasi masyarakat diperlukan untuk mengawasi pelaksanaan invovasi, bukan hanya masyarakat sebagai pengguna tetapi berkontribusi untuk memberikan berbagai masukan melalui saluran yang ada seperti melalui kelompok kepentingan (wartawan, Lembaga Swadaya Masyarakat) dan melalui masukan para akademisi untuk mengembangkan inovasi dan mewujudkan tingkat partisipasi masyarakat, agar pemanfaatn inovasi terlaksana dengan baik.

Salah satu faktor yang penting dalam mengembangkan inovasi adalah partisipasi masyarakat (Alberti \& Bertucci, 2007; Moore \& Hartley, 2008) karena mereka adalah objek pelayanan. Kritikan dan saran dari masyarakat menjadi penting untuk pertimbangan pengembangan inovasi lebih lanjut. Faktanya partisipasi masyarakat di Kabupaten Aceh Tenggara masih rendah. Fakta ini dapat dilihat dari sifat apatis masyarakat turut memberikan kontribusi partisipasi masyarakat rendah. Ketika sosialisasi dilakukan sebagian besar masyarakat tidak merespon dengan positif,

Selain partisipasi masyarakat, pengguna inovasi juga memberikan pengaruh terhadap pengembangan inovasi. Pengguna inovasi (institusi pemerintah lainnya) lebih banyak menerima hasil akhir 
inovasi dari institusi lain. Penerimaan itu diakibatkan oleh kesamaan institusi milik negara yang diatur dengan aturan pemerintah. Tidak semua hasil akhir inovasi dapat dipergunakan, namun secara umum penggunaan itu bersifat instruktif.

Pengguna akan menjadi sumber informasi untuk mengembangkan dan mengevaluasi inovasi yang ada. Sebagai contoh, Kabupaten Padang Pariaman, Pemerintah Kabupaten Klungkung, Kabupaten Badung, Kabupaten Situbondo, dan Kabupaten Tanah Datar. Daerah-daerah ini memiliki cara tersendiri untuk turun langsung di tengah masyarakat. Sepeda motor dan mobil digunakan untuk menjangkau titik-titik tertentu (daerah terpencil, pusat keramaian), serta untuk koordinasi antara institusi pelaksana administrasi kependudukan. Sederhananya, ketika pemerintah memberikan kemudahan, secara otomatis masyarakat akan merespon hal itu dengan tingkat partisipasi yang semakin meningkat.

\section{Service Function of Government}

Fenomena buruknya pelayaan publik oleh birokrasi menjadi perhatian serius bagi pemerintah. Pemerintahan Inggris misalnya menekankan agar pemerintah daerah memberikan 85 persen layanan masyarakat kepada sektor swasta (Erridge, 2009), namun di Indonesia hal itu belum sepenuhnya terwujud. Raadschelders (2003) memberikan alasan mengapa hal itu terjad. Beberapa alasan disampikan antara lain seperti masalah anggaran, adanya upaya mengembalikan kepercayaan publik, serta sifat tertutup birokrasi dengan karakteristik yang masih tradisional. Menindaklanjuti apa yang disampaikan Raadschelders tersebut, maka fungsi pelayanan pemerintah saat ini lebih terbuka, mudah diakses, serta dapat dipertanggungjawabkan. Teknologi memberi kemudahan untuk koordinasi, keterbukaan dan aksesibilitas saat ini sering dilakukan melalui radio, televisi, komputer, jaringan informasi seperti $e$-mail dan internet. Sederhananya pemanfaatan teknologi dapat memengaruhi institusi itu sendiri. Agar fungsi pelayanan oleh pemerintah dapat terealisasi dengan baik.

Pemanfaatan teknologi sering digunakan untuk memperbaiki pelayanan pemerintah. Dalam kasus perekaman data dan dokumen kependudukan di Kabupaten Aceh Tenggara pemanfaatan teknologi secara maksimal belum menunjukkan hasilnya. Contoh, dari 16 kecamatan yang ada di Kabupaten Aceh Tenggara belum mendapatkan jangkauan jaringan yang terhubung dengan server pada kantor Dinas Kependudukan dan Pencatatan Sipil Kabupaten. Disisi lain masih ada kecamatan yang tidak online melakukan perekaman KTP-el karena ketiadaan jaringan.Salah satu penyebab adalah kurangnya pemeliharaan terhadap pengadaan jaringan yang dilakukan pemerintah pusat dan pihak ketiga. Bahkan kondisi geografis serta ketiadaan instruktur merupakan faktor penghambat rendahnya pelayanan perekaman KTP-el di tengah masyarakat.

Begitu juga dengan pembuatan dokumen kependudukan harus dilakukan di kantor Dinas Kependudukan dan Pencatatan Sipil Kabupaten. UndangUndang Nomor 24 Tahun 2013 pasal 8 angka 3 menjelaskan bahwa Pelayanan Pencatatan Sipil pada tingkat kecamatan dilakukan oleh UPT Instansi Pelaksana dengan kewenangan menerbitkan Akta Pencatatan Sipil. Pelimpahan wewenang dari pimpinan daerah ke kecamatan belum pernah dilakukan dan akan memaksa masyarakat akan terus mengeluarkan biaya untuk memperbaharui dokumen kependudukan.

Bagi masyarakat dengan penghasilan rendah, keadaan ini sangat memberatkan. Akan tetapi suka ataupun tidak masyarakat sangat membutuhkan identitas diri serta dokumen kependudukan lainnya.

Pengeloaan inovasi yang baik tidak dapat berdiri sendiri, Ada beberapa faktor yang memengaruhi implementasi inovasi, misalnya proses politik yang kondusif 
antara legislatif dan eksekutif, adnya kesepakatan anggaran antara legislatif dan eksekutif, proses perencanaan serta keputusan terhadap kebijakan yang ditempuh, kemampuan pengetahuan manajerial pimpinan, kerjasama lintas batas untuk mengelola inovasi dan mengembangkan inovasi (Anttiroiko, Bailey, \& Valkama, 2011).

Cara terbaik evaluasi itu diawali dengan kriteria sederhana untuk menentukan apakah sebuah ide/cara, pelaksanaannya akan berlanjut ke evaluasi yang lebih mendalam. Kriteria evaluasi ini mungkin terkait erat dengan anggaran, sumber daya manusia, kebijakan, dan apapun kriteria evaluasi tersebut harus diperjelas bahwa kegagalan dan kesuksesan inovasi bukanlah sebuah alasan pragmatis. Mungkin saja inovasi ditentukan dengan cara dilaksanakan dengan biaya lebih rendah, pengelolaan yang baik, dan dukungan sumber daya yang memadai. Pengelolaan inovasi pada birokrasi sangat penting diungkapkan untuk menghindari kegagalan inovasi, karena inovasi dalam aktivitas birokrasi pemerintah akan menggunakan anggaran negara yang tidak sedikit dan berimplikasi kepada pelayanan publik yang baik.

\section{KESIMPULAN DAN REKOMENDASI Kesimpulan}

Gerakan Indonesia Sadar Adminduk (GISA) adalah gerakan yang dicanangkan pemerintah pada tahun 2017 untuk memberikan kesadaran kepada masyarakat pentingya dokumen kependudukan yang benar dan sadar akan manfaatnya. Bukan hanya masyarakat yang diberikan kesadaran namun petugas dan institusi pengguna turut menjadi sasaran gerakan ini. Gerakan ini sepertinya merupakan respon pemerintah untuk menanggapi banyaknya masyarakat yang belum terekam. Oleh sebab itu pemerintah daerah didorong untuk melakukan berbagai inovasi untuk melacak dan menertibkan administrasi kependudukan. Inovasi itu juga harus dikelola dengan cara-cara yang inovatif, namun inovasi tidak mudah dilakukan dalam aktivitas pemerintah. Upaya ini mendorong pemerintah daerah untuk terus melakukan reformasi dengan meningkatkan kapasitas, kamampuan, integritas dalam melaksanakan tugasnya. Reformasi dan inovasi sering gagal dan menghilang meskipun perubahan sistem telah dilakukan, dan sering bertolak belakang dengan tuntutan masyarakat.

Di saat yang sama tata kelola inovasi akan melibatkan perubahan sistem produksi dari instrumen pemerintah untuk mencapai tujuan. Inovasi akan merubah sistem produksi yang melintasi batas-batas organisasi, tidak hanya dari jangkauan sumber daya untuk diperbesar dan meningkatkan kinerja sistem produksi. Dan juga melibatkan perubahan dengan instrumen yang digunakan pemerintah. Lebih sering perubahan dalam bentuk organisasi, pengaturan, perencanaan dan layanan, serta inovasi yang memberikan partisipasi publik dalam desain pengiriman layanan tertentu. Ketika kita mengubah tata kelola publik dengan cara yang benar, inovasi dapat didorong untuk kepentingan pengguna dan penerima pada umumnya. Dengan demikian, keseimbangan antara paradigma tata kelola yang berbeda akan memacu produksi inovasi publik dan membawa solusi baru yang akan mengungguli yang sudah ada. Sederhananya sistem yang ada tidak bisa lagi memenuhi tuntutan masyarakat yang semakin kompleks.

\section{Rekomendasi}

Beberapa saran dapat dikemukakan sebagai inti dari penelitian ini adalah pertama bagi pemerintah pusat maupun daerah menjalankan inovasi bukanlah sesuatu yang mudah untuk diterapkan, inovasi itu perlu dikelola dengan cara-cara yang inovatif juga. Alasannya inovasi akan dapat menunjukkan hasilnya ketika inovasi itu didukung oleh kebijakan, sumber daya, manajerial dan infrastruktur. Kedua bagi 
pimpinan daerah, harus beralih kearah transformasional, pemimpin transformasional akan memahami bahwa budaya pemimpin tidak dimulai dengan dokumen tertulis, melainkan oleh model perilaku yang mereka tampilkan setiap hari apakah dalam urusan perencanaan, mengelola, memimpin, pengawasan, pengambilan keputusan atau bahkan pelimpahan wewenang kepada bawannya untuk membangun relasional dan perubahan yang riil. Akhirnya bagi peneliti lain agar dapat memberikan wawasan pengetahuan dengan melakukan kajian, dan penelitian empiris masa depan agar dapat mengungkapkan berbagai macam pengelolaan inovasi dengan cara inovatif. Setidaknya penelitian ini bisa menjadi dasar penelitian pendahuluan sebagai kerangka untuk menjawab cara mengelola inovasi yang pernah dilakukan.

\section{DAFTAR PUSTAKA}

\section{Buku}

Alberti, A., \& Bertucci, G. 2007. Innovation in Governance and Public Administration: Key Issues and Perspectives. Dalam Department of Economic and Social Affairs (Ed.). Innovations in Governance in the Middle East, North Africa, and Western Balkans: Making Governments Work Better in the Mediterranean Region (h. 3-12). New York: United Nations.

Anttiroiko, A.-V., Bailey, S. J., \& Valkama, P. 2011. Innovations in Public Governance in the Western World. Amsterdam: IOS Press BV.

Aspinall, E., \& Sukmajati, M. 2015. Politik Uang di Indonesia: Patronase dan Klientelisme pada Pemilu Legislatif 2014. Yogyakarta: PolGov.

Assche, K. V., Beunen, R., \& Duineveld, M. 2014. Evolutionary Governance Theory: An Introduction. Heidelberg: Springer Science+Business Media.

Banerjee, B., \& Ceri, S. 2016. Creating Innovation Leaders A Global
Perspective. Switzerland: Springer International Publishing.

Bovaird, T., \& Löffler, E. 2009. Public Management and Governance (2nd ed.). New York, NY: Routledge.

Caiden, G. E. 2009. Administrative Reform. Chicago: Aldine Transaction.

DuBrin, A. J. 2006. Essential of Management (9th ed.). Mason, OH: Cengage Learning.

Dwiyanto, A. 2015. Reformasi Birokrasi Kontekstual. Yogyakarta: Gadjah Mada University Press.

Ernst, \& Young. 2017. Public Sector Innovatiom: From Idea to Action. Canada: Ernst \& Young LLP.

Erridge, A. 2009. Contracting for Public Services. Dalam T. Bovaird, \& E. Loffler (Ed.). Public Management and Governance (h.95-108). Oxon: Routledge.

Fagerberg, J. 2004. Innovation: A Guide to the Literature. Dalam J. Fagerberg, D. C. Mowery, \& R. R. Nelson (Ed.). The Oxford Handbook of Innovation (h. 126). New York: Oxford University Press.

Farazman, A. 2009. Bureaucracy and Administration. Boca Raton: CRC Press.

Farmer, D. J. 2010. Public Administration in Perspective: Theory and Practice Through Multiple Lenses. New York: M.E. Sharpe.

Francisco, J. 2012. Innovation in Government? Let's Get Practical. Ottawa: Canadian Government Executive.

Goodsell, C. T. 2015. New Case Bureaucracy. Washington, DC: CQ Press.

Hummel, R. P. 2015. The Bureaucractic Experience: The Post Modern Challenge (5th ed.). Oxon: Routledge.

Klareskov, V., \& Nikolov, D. 2007. Eleven Innovations in Governance in the Middle East, North Africa, and Western Balkans: A Synopsis. Dalam 
Department of Economic and Social Affairs (Ed.). Innovations in Governance in the Middle East, North Africa, and Western Balkans: Making Governments Work Better in the Mediterranean Region (h. 41-52). New York: United Nations.

Miles, I. 2004. Innovation in Service. Dalam J. Fagerberg, D. C. Mowery, \& R. R. Nelson (Ed.). The Oxford Handbook of Innovation (h. 433-458). New York: Oxford University Press.

Morris, L. 2013. The Innovation Master Plan - Tyngsborough, MA: Innovation Academy.

Moustakas, C. 1994. Phenomenological Research Methods. Thousand Oaks, CA: SAGE Publications.

Raadschelders, J. C. 2003. Government A Public Administrative Perspective. New York: Routledge.

Rogers, E. M. 1995. Diffusion of Innovations (4th ed.). New York: The Free Press.

Shafritz, J. M., Russel, E., \& Borick, C. P. 2016. Introducing Public Administration (8th ed.). Oxon: Routledge.

Torfing, J., \& Triantafillou, P. 2016. Enhancing Public Innovation by Transforming Public Governance. Cambridge: Cambridge University Press.

Willoughby, K. G. 2014. Public Budgeting in Context: Structure, Law, Reform, and Results. San Francisco, CA: John Wiley \& Sons.

\section{Jurnal}

Agger, A., \& Sorensen, E. 2016. Managing Collaborative Innovation in Public Bureaucracies. Planning Theory, 1-21. doi:10.1177/1473095216672500

Andhika, L. R. 2017. Perbandingan Konsep Tata Kelola Pemerintah: Sound Governance, Dynamic Governance, dan Open Government. Jurnal Ekonomi dan Kebijakan Publik, 8(2), 87-102. doi:10.22212/jekp.v8i2.867
Bannink, D., \& Ossewaarde, R. 2012. Decentralization: New Modes of Governance and Administrative Responsibility. Administration \& Society, 44(5), $595-624$. doi:10.1177/0095399711419096

Bannink, D., \& Ossewaarde, R. 2012. Decentralization: New Modes of Governance and Administrative Responsibility. Administration \& Society, 44(5), $595-624$. doi:10.1177/0095399711419096

Baregheh, A., Rowley, J., \& Sambrook, S. 2009. Towards a Multidisciplinary Definition of Innovation. Management Decision, 47(8), 1323-1339. doi:10.1108/00251740910984578

Berman, E. M. 2007. Innovation in Local Government: Past, Present, Future. International Journal of Public Administration, 19(7), 1027-1036. doi:10.1080/01900699608525130

Borins, S. 2002. Leadership and Innovation in the Public Sector. Leadership \& Organization Development Journal, 23(8), 467-476. doi:10.1108/01437730210449357

Bryson, J. M., Quick, K. S., Slotterback, C. S., \& Crosby, B. C. 2012. Designing Public Participation Processes. Public Administration Review, 73(1), 23-34. doi:10.111/j.15406210.2012.02678.x.

Callahan, K. 2007. Citizen Participation: Models and Methods. International Journal of Public Administration, 30(11), 1179-1196. doi:10.1080/01900690701225366

Cerne, M., Jaklic, M., \& Skerlavaj, M. 2013. Authentic Leadership, Creativity, and Innovation: A Multilevel Perspective. Leadership, 9(1), 63-85. doi:10.1177/1742715012455130

Cooper, C. A., \& Reinagel, T. P. 2015. The Limits of Public Service Motivation: Confidence in Government Institutions Among Public Servant. Administration \& Society, 89(9), 1297- 
1317.

doi:10.1177/0095399715581039

Damanpour, F. 1996. Bureaucracy and Innovation Revisited: Effects of Contingency Factors, Industrial Sectors, and Innovation Characteristics. The Journal of High Technology Management Research, 7(2), 149-173. doi:10.1016/S10478310(96)90002-4

Damanpour, F., \& Aravind, D. 2011. Managerial Innovation: Conceptions, Processes, and Antecedents. Management and Organization Review, $8(2), \quad 423-454$. doi:10.1111/j.17408784.2011.00233.x

Denhardt, J. V., \& Denhardt, R. B. 2015. The New Public Service Revisited. Public Administration Review, 75(5), 664672. doi:10.1111/puar.12347

Giorgi, A. 1997. The Theory, Practice, and Evaluation of the Phenomenological Method as a Qualitative Research. Journal of Phenomenological Psychology, 28(2), 235-260. doi:10.1163/156916297X00103

Groenewald, T. 2004. A Phenomenological Research Design Illustrated. International Journal of Qualitative Methods, 3(1), 42-55. doi:10.1177/160940690400300104

Hartley, J. 2005. Innovation in Governance and Public Services: Past and Present. Public Money \& Management, 25(1), 27-34. doi:10.1111/j.14679302.2005.00447.x

Ho, K. L. 2011. Reinventing the Bureaucracy? Malaysia's New Administrative Reform Initiatives. Journal of Comparative Asian Development, 1(1), 87-104. doi:10.1080/15339114.2002.967835 1

Kim, S., \& Han, C. 2014. Administrative Reform in South Korea: New Public Management and the Bureaucracy. International Review of Administrative
Science, $\quad 0(0), \quad 1-19$. doi:10.1177/0020852314558034

Klimentova, S. 2014. Innovation in the Public Sector: Is it Measurable. Studies in Managerial and Financial Accounting, 28, 289-315. doi:10.1108/S1479351220140000028021

Lewis, J. M., Ricard, L. M., \& Klijn, E. H. 2017. How Innovation Drivers, Networking and Leadership Shape Public Sector Innovation Capacity. International Review of Administrative Science, 1-20. doi:10.1177/0020852317694085

McHugh, M., O'Brien, G., \& Ramondt, J. 2010. Finding an Alternative to Bureaucratic Models of Organization in the Public Sector. Public Money \& Management, 21(1), 35-42. doi:10.1111/14679302.00246

Moore, M., \& Hartley, J. 2008. Innovations in Governance. Public Management Review, 10(1), 3-20. doi:10.1080/14719030701763161

Osborne, S. P., \& Brown, L. 2011. Innovation, Public Policy and Public Service Delivering in the UK: The Word that Would be King? Public Administration, 89(4), 1335-1350. doi:10.1111/j.14679299.2011.01932.x

Rasul, I., \& Rogger, D. 2017. Management of Bureaucrats and Public Service Delivery: Evidence from the Nigerian Civil Service. The Economic Journal, $O(0), 1-29$. doi:10.1111/ecoj.12418

Scupola, A., \& Zanfei, A. 2016. Governance and Innovation in Public Sector Services: The Case of the Digital Library. Government Information Quarterly, 33(2), 237-249. doi:10.1016/j.giq.2016.04.005

Sjahrir, B. S., Kis-Katos, K., \& Schulze, G. 2013. Political Budget Cycles in Indonesia at the District Level. Economics Letters, 120(2), 342-345. doi:10.1016/j.econlet.2013.05.007 
Sorensen, E., \& Torfing, J. 2011. Enhancing Collaborative Innovation in the Public Sector. Administration \& Society, 43(8), 842-868. doi:10.1177/0095399711418768

$\mathrm{Su}, \mathrm{S} .$, \& Baird, K. 2017. The Role of Leaders in Generating Management Innovation. The International Journal Human Resource Management, 1-22. doi:10.1080/09585192.2017.128253 3

Vries, H. d., Bekkers, V., \& Tummers, L. 2015. Innovation in the Public Sector: A Systematics Review and Future Research Agenda. Public Administration, 94(1), 146-166. doi:10.1111/padm.12209

Wisdom, et al. (2014). Innovation Adoption: A Review of Theories and Constructs. Adm Policy Ment Health, 41(4), 480502. doi:10.1007/s10488-013-0486-4

\section{Disertasi}

Chung, C.-c. (2011). Government, Governance and the Development of the Innovation Systems: The Example of the Taiwanese Biotechnology and Related Sectoral Policies . University of Manchester. Manchester, UK.

Thomas, G. (2015). Constructing The Hydrogen Fuel Cell Community: A Case Study of Networked Innovation Governance. Dissertation Submitted in degree of Doctor of Philosophy, University of Birmingham, Birmingham, UK.

\section{Sumber Digital}

Andayani, D. (2017, 9 19). Kemendagri: 9,3 Juta WNI Belum Rekam e-KTP. Diperoleh tanggal 12 Maret 2018, dari https://news.detik.com/berita/d3649856/kemendagri-93-juta-wnibelum-rekam-e-ktp

Disdukcapil Kabupaten Gunung Kidul. (2016, 11 23). Inovasi pelayanan di Dinas Kependudukan dan Pencatatan Sipil Kabupaten Gunungkidul. Diperoleh tanggal 12 Maret 2018, dari http://dukcapil.gunungkidulkab.go.id /inovasi-pelayanan-di-dinas-

kependudukan-dan-pencatatan-sipilkabupaten-gunungkidul/

Dirjen Dukcapil. (2014, Pebruari 27). Sejarah KTP di Indonesia. Diperoleh tanggal 12 Maret 2018, dari http://www.dukcapil.kemendagri.go.i d/detail/sejarah-ktp-di-indonesia

Dirjen Dukcapil. 2016 (Desember 30). Ditjen Dukcapil Apresiasi Inovasi Dinas Dukcapil Kabupaten Situbondo. Diperoleh tanggal 22 Maret 2018, dari http://www.dukcapil.kemendagri.go.i d/detail/ditjen-dukcapil-apresiasiinovasi-dinas-dukcapil-kabupatensitubondo

Dirjen Dukcapil. 2017 (Mei 5). Dinas Dukcapil Tanah Datar Masuk Top 40 Inovasi Pelayanan Publik. Diperoleh tanggal 4 April 2018, dari http://www.dukcapil.kemendagri.go.i d/detail/dinas-dukcapil-tanah-datarmasuk-top-40-inovasi-pelayananpublik

Dirjen Dukcapil. 2018 (Pebruari 2). Luncurkan Si Dukun, DKI Layani 6 In 1 Dokumen Kependudukan. Diperoleh tanggal 11 April 2018, dari http://www.dukcapil.kemendagri.go.i d/detail/luncurkan-si-dukun-dkilayani-6-in-1-dokumenkependudukan-3

Kemenpan. 2016 (Maret 14). Kementerian PANRB Tetapkan Top 99 Inovasi Pelayanan Publik 2016. Diperoleh tanggal 11 April 2018, dari https://www.menpan.go.id/beritaterkini/4516-kementerian-panrbtetapkan-top-99-inovasi-pelayananpublik-2016

Disdukcapil Kabupaten Klungkung,. 2017 (Maret 10). Predator Berkeliaran Urus E-KTP Masyarakat Klungkung. Diperoleh tanggal 17 April 2018, dari https://www.disdukcapil.klungkungk ab.go.id/baca-artikel/27/Predator- 
Berkeliaran-Urus-EKTP-MasyarakatKlungkung.html

OECD. 2016 (Nopember 15). Observatory of Public Sector Innovation. Diperoleh tanggal 23 Pebruari 2018, dari https://www.oecd.org/governance/o bservatory-public-sectorinnovation/innovations/page/larasit areachingtheunreached.htm

Disdukcapil Kabupaten Pariaman. 2017 (Desember 29). Raih Zona Hijau, Disdukcapil Padang Pariaman Terus Tingkatkan Kualitas Pelayanan. Diperoleh tanggal 17 April 2018, dari http://dukcapil.padangpariamankab. go.id/index.php?option=com_content \&view=article\&id=187:zonahijau\&cat $\mathrm{id}=88$ : berita\&Itemid $=2327$

\section{Laporan}

Population Reference Bureau. (2017). 2016 World Population Data Sheet. Washington DC: Inform Empower Advance.

Disdukcapil Kabupaten Aceh Tenggara. (2017). Laporan Data Perekaman Penduduk Kabupaten Aceh Tenggara Tahun 2017. Kutacane: Dinas Kependudukan dan Pencatatan Sipil Kabupaten Aceh Tenggara.

\section{Peraturan Perundang-undangan}

Undang-Undang Republik Indonesia Nomor 24 Tahun 2013 tentang Administrasi Kependudukan

Undang-Undang Republik Indonesia Nomor 23 Tahun 2014 tentang Pemerintahan Daerah.

Qanun Kabupaten Aceh Tenggara Nomor 80 Tahun 2013 Tentang Pelaksanaan Tugas dan Fungsi Dinas Kependudukan dan Pencatatan Sipil Kabupaten Aceh Tenggara. 